\title{
Cathepsin-G Interferes with Clearance of Pseudomonas aeruginosa from Mouse Lungs
}

\author{
JULIA SEDOR, LISA HOGUE, KATHRYN AKERS, SARAH BOSLAUGH, JOHN SCHREIBER, AND THOMAS FERKOL \\ Mallinkrodt Department of Pediatrics [J.S., L.H., K.A., S.B., T.F.], WA University School of Medicine, St. Louis, MO 63110; \\ Department of Pediatrics [J.S.], University of Minnesota School of Medicine, Minneapolis, MN 55455
}

\begin{abstract}
The cystic fibrosis airway is susceptible to Pseudomonas aeruginosa infection, which stimulates an intense inflammatory response leading to airway obstruction and bronchiectasis. Neutrophils migrate into the airway, and once there, release high concentrations of neutral serine proteases during phagocytosis and in death. In particular, neutrophil elastase is central to progression of bronchiectasis by interfering with bacterial clearance and directly perpetuating the inflammatory response in the airway. Using a murine model of endobronchial inflammation, we found that a different neutrophil-derived serine protease, cathepsin G, inhibited the host's ability to clear Pseudomonas from the lung, based on a 1-log reduction in bacteria recovered from cathepsin G-deficient mice. Higher antibody concentrations were found in respiratory epithelial lining fluid from mice lacking cathepsin G, but there was no difference in other opsonins, such as surfactant proteins A and D. Chemokine levels measured in the lung correlated with bacterial burden and not the animal's genotype, indicating that airway inflammation was not affected by the presence (or absence) of specific serine proteases. These findings suggest that cathepsin $\mathrm{G}$ interferes with airway defenses, showing that proteases other than neutrophil elastase have roles in the pathogenesis of suppurative airway diseases.
\end{abstract}

(Pediatr Res 61: 26-31, 2007)

$\mathrm{P}^{\mathrm{e}}$ ersistent lung infection, typically with Pseudomonas aeruginosa, and an unremitting inflammatory response are the major causes of morbidity and mortality in cystic fibrosis (CF). The exaggerated inflammatory response is characterized by a massive influx of neutrophils across the respiratory epithelium (1). This neutrophil excess brings with it an abundance of serine proteases, such as neutrophil elastase (NE), cathepsin $\mathrm{G}(\mathrm{CG})$, and proteinase 3, which are lytic enzymes with a wide range of substrates. Intracellular NE has been shown to be necessary for bacterial killing and host defense $(2,3)$. However, during phagocytosis or in death, neutrophils release their contents into the airways, and active enzymes overwhelm native antiproteases contributing to the pathogenesis of CF lung disease. In particular, NE has been shown to incite inflammatory responses $(4,5)$, interfere with bacterial clearance $(6,7)$, and disrupt innate immunity $(8,9)$.

Received April 18, 2006; accepted August 27, 2006.

Correspondence: Thomas Ferkol, M.D., Division of Pediatric Allergy and Pulmonary Medicine, Department of Pediatrics, 660 South Euclid Avenue, Mailbox 8202, St. Louis, MO, 63110; e-mail: ferkol_t@kids.wustl.edu

This work was supported by grants from the Cystic Fibrosis Foundation and National Institutes of Health, HL64044.

DOI: 10.1203/01.pdr.0000250043.90468.c2
The roles of other neutrophil-derived serine proteases are less clear, but they are likely to be clinically relevant and could have effects distinct from NE. An abundant protein in human and murine neutrophils (10) CG activates airway epithelial cells and induces secretion from airway submucosal glands (11). It has a number of potential substrates in the $\mathrm{CF}$ lung and has been shown to cleave components of the extracellular matrix in vitro, although less efficiently than NE (12). Moreover, it can regulate innate immunity and inflammation through cleavage or proteolytic inactivation of collectins, cytokines, complement, and cell surface receptors $(13,14)$. Cathepsin $\mathrm{G}$ has been shown to be important for neutrophils to respond to chemotactic signals (15), and has some antimicrobial activity against pathogens $(16,17)$.

In these experiments, we examined the effects of $\mathrm{CG}$ in the infected lung, testing the hypothesis that CG interferes with bacterial clearance and escalates the pulmonary inflammatory response. Unlike previous studies which used antiproteases to indiscriminately neutralize the effects of serine proteases $(6,18)$, we examined bacterial clearance and airway inflammation in vivo in the absence of selected proteases using a well-established model of Pseudomonas endobronchitis in mice genetically altered to lack NE or CG.

\section{MATERIALS AND METHODS}

\begin{abstract}
Animals. Protease-deficient $\left(n e^{-/-} \mathrm{cg}^{+/+}, n e^{+/+} \mathrm{cg}^{-/-}\right.$, and $\left.n e^{-/-} \mathrm{cg}^{-/-}\right)$ mice previously created by homologous recombination were used in these experiments $(2,19,20)$. To control for mouse genetic background, proteasesufficient mice $\left(n e^{+/+} \mathrm{cg}^{+/+}\right)$of the same strain were used as controls, i.e. wild-type SvJ strain was used as controls in experiments with $\mathrm{ne}^{-/-} \mathrm{cg}^{+/+}$and $n e^{-1-} \mathrm{cg}^{-1-}$ mice, and wild-type $129 / \mathrm{SvJ}$ strain served as control for the $n e^{+/+} \mathrm{cg}^{-/-}$mice. The genotype of individual animals was established by Southern blot hybridization of genomic DNA isolated from the animal's tail using established protocols. Finally, all research conformed to National Institutes of Health guidelines, and the protocol was reviewed and approved by the Washington University School of Medicine Animal Studies Committee.
\end{abstract}

Murine model of endobronchial inflammation. An adaptation of the agarose bead method was used to create a neutrophilic endobronchitis in mice (21). Mice underwent intratracheal inoculation with sterile agarose beads or beads embedded with nonmucoid $P$. aeruginosa (PAO1). A silastic catheter was inserted transtracheally and $50 \mu \mathrm{L}$ of a 1:10 dilution of bead slurry $\left(5.0 \times 10^{4} \mathrm{P}\right.$. aeruginosa $\left.\mathrm{CFU} / \mathrm{lung}\right)$ was instilled into the right mainstem bronchus.

Bronchoalveolar lavage. Based on previous data examining maximum bacterial burden and inflammation in this infection model, bronchoalveolar

Abbreviations: BAL, Bronchoalveolar lavage; CG, cathepsin G; CF, cystic fibrosis; NE, neutrophil elastase; SP, surfactant protein 
lavage (BAL) was performed $3 \mathrm{~d}$ after infection using established techniques (21).

ELISA for secreted cytokines. Pro-inflammatory cytokine, TNF- $\alpha$, and CXC chemokines (MIP-2 and $\mathrm{KC}$ ) were measured in BAL fluid and lung homogenates in vivo using commercially available ELISA (R \& D Systems, Minneapolis, MN) as described previously (21). Protein concentrations were corrected for the volume of respiratory epithelial lining fluid (ELF) recovered by measuring urea dilution (22).

Phagocyte isolation. Mice lacking neutrophil serine proteases and their wild-type littermates underwent intraperitoneal injection with $15 \%$ glycogen, and $3 \mathrm{~h}$ later, peritoneal exudates were collected and washed with Hanks buffered saline solution. Polymorphonuclear cells were separated from other inflammatory cells by Ficoll density gradient centrifugation, and contaminating erythrocytes were removed by hypotonic lysis (2). To isolate murine macrophages, the animals underwent intraperitoneal injection with thioglycollate and underwent peritoneal washings $3 \mathrm{~d}$ later using established techniques (23).

Measurement of cathepsin $G$ and neutrophil elastase activity. Based on established techniques, functional activity of serine proteases in cell lysates and BAL samples from experimental animals were measured using specific peptide chromogenic substrates of NE and CG, respectively (Elastin Products, Owensville, MO) (23).

Immunoblot analyses for murine immunoglobulins. Using nonreducing conditions, proteins from BAL fluid were separated by SDS-PAGE and transferred onto nylon membranes using standard techniques. The blots were blocked with PBS, $\mathrm{pH} 7.4,0.03 \%$ polyoxyethylenesorbitan monolaurate, and $10 \%(\mathrm{wt} / \mathrm{vol})$ dry skim milk for $1 \mathrm{~h}$ at room temperature, then incubated at room temperature with horseradish peroxidase conjugated, goat-derived, antimIgG or anti-mIgA antibodies (Sigma Chemical Co., St. Louis, MO). The membranes were washed, then Western blot enhanced chemiluminescence detection solution (Amersham, Arlington Heights, IL) was applied for 1 min. Luminescence emitted from the filter was detected by exposure to photographic film.

ELISA for murine antibodies in BAL fluid. Lavage fluid was analyzed for mouse antibodies using established ELISA. To assess for specific antiPseudomonas antibodies, P. aeruginosa was grown to an OD of 0.5 at 650 $\mathrm{nm}, 100 \mu \mathrm{L}$ of the bacterial culture was applied to each well of a 96-well flat-bottomed ELISA plate, and incubated overnight at $4^{\circ} \mathrm{C}$. The cells were washed with PBS containing $0.5 \%$ BSA and $0.005 \%$ polyoxyethylenesorbitan monolaurate, then blocked with $0.5 \%$ BSA in PBS. The wells were washed, and $50 \mu \mathrm{L}$ of BAL fluid was applied to each well for $1 \mathrm{~h}$ at room temperature. After additional washings, bound $\mathrm{mIgG}$ or $\mathrm{mIgA}$ was detected by incubation with 1:1000 dilution of horseradish peroxidase-conjugated anti-mouse IgG or IgA secondary antibody (Sigma Chemical Co. Immunochemicals, St. Louis, $\mathrm{MO}$ ). Irrelevant, conjugated anti-mouse antibody was used as controls. Treated with TMB Microwell Peroxidase Substrate system, absorbance was measured at $450 \mathrm{~nm}$.

Surfactant protein A and Dd analyses. Quantitative analyses for SP-A and SP-D in BAL fluid were performed using a double-capture ELISA as described previously $(24,25)$.

Quantitative bacteriology. To examine the effect of neutrophil proteases on bacterial clearance, right lung lobes of mice inoculated with infected agarose beads were removed aseptically, homogenized in $1 \mathrm{~mL}$ PBS, and cultured quantitatively using serial dilution on tryptic soy agar plates (21).

Flow cytometry. Mice were infected with green fluorescent protein (GFP)expressing PAO1 using the agarose bead model, and $3 \mathrm{~d}$ after bacterial inoculation the lungs were perfused to clear intravascular leukocytes and erythrocytes from the pulmonary circulation. The right lung was removed, homogenized briefly in $1 \mathrm{~mL}$ PBS, and passed through a preseparation filter (Miltenyi Biotec, Auburn, CA) to obtain a single cell suspension. Isolated cells were incubated with R-phycoerythrin (RPE)-conjugated rat-derived, anti-mouse neutrophil antibody (Serotec, Raleigh, NC) (1:10 dilution) for $1 \mathrm{~h}$ at $4{ }^{\circ} \mathrm{C}$ in the dark. After incubation, cells were washed with $1 \mathrm{~mL}$ cold PBS containing $1 \%$ fetal bovine serum and $0.1 \%$ sodium azide, then centrifuged at $2000 \mathrm{rpm}$ for $5 \mathrm{~min}$. The process was repeated twice, and cells were re-suspended in $500 \mu \mathrm{L} 1 \%$ paraformaldehyde. The degree of cell fluorescence was identified using EPICS-Elite ESP Coulter Fluorescence Activated Cell Sorter.

Statistical analysis. Data are expressed as means \pm SE (SEM). Statistical comparisons between control and the various protease-deficient groups were made using unpaired Student $t$-tests or single-factor ANOVA. For samples that were not normally distributed, Kruskal-Wallis or Mann-Whitney tests were applied. The relationship between pulmonary inflammation and bacterial burden was examined by determining the Pearson product moment correlation coefficient and least squares linear regression analysis.

\section{RESULTS}

Serine protease content of murine neutrophils. In the initial experiments, the serine protease phenotype of neutrophils from the different mouse models was confirmed. As expected, wild-type neutrophils contained high amounts of both NE (38 $\left.\mu \mathrm{mol} / 10^{6} \mathrm{pmn}\right)$ and CG $\left(70 \mu \mathrm{mol} / 10^{6} \mathrm{pmn}\right)$. Cells isolated from NE-deficient mice expressed CG (40 $\mu \mathrm{mol} / 10^{6} \mathrm{pmn}$ ) but no NE, while CG-deficient mice contained $\mathrm{NE}\left(61 \mu \mathrm{mol} / 10^{6} \mathrm{pmn}\right)$ but undetectable CG activity.

Bacterial clearance and endobronchial inflammation in protease-deficient mice. To examine the roles of NE and CG in bacterial clearance from the lungs of protease-deficient mice, animals with the same genetic background and deficient in $\mathrm{NE}$ $\left(\mathrm{cg}^{+/+} n e^{-/-}\right)$(2) or both neutrophil proteases $\left(\mathrm{cg}^{-/-} n e^{-/-}\right)(20)$ were challenged with Pseudomonas-laden agarose beads. Wildtype mice $\left(\mathrm{cg}^{+/+} n e^{+/+}\right)$of the same strain background, replete with neutrophil proteases, served as controls.

Before infection, pulmonary histology was normal and similar between mouse genotypes (data not shown). After inoculation with $P$. aeruginos $a$-laden beads, there was no difference between mouse genotypes in clinical outcomes, including survival (no mortality in any group after infection), histopathologic appearance of the lungs (data not shown), and weight loss $\left(\mathrm{cg}^{+/+} n e^{+/+}: 17.9 \pm 4.0 \%, n=16 ; \mathrm{cg}^{+/+} n e^{-/-}: 21.7 \pm 4.4 \%\right.$, $n=14$; and $c g^{-/-} n e^{-/-}: 20.2 \pm 3.1, n=16$ ). Three days after intratracheal inoculation with $P$. aeruginos $a$, lungs were removed and quantitative bacterial examinations of lung homogenates were performed to determine whether the bacterial burden differed among the genotypes. No difference was detected in the bacterial loads in lungs from $\mathrm{cg}^{+/+} \mathrm{ne}^{+/+}$and $\mathrm{cg}^{+/+} \mathrm{ne}^{-/-}$mice, but there was a log reduction in viable bacteria recovered from $\mathrm{cg}^{-/} n e^{-/-}$mice (Fig. 1A). This phenotype was also found in the infected lungs of CG-deficient mice compared with isogenic, wild-type, control mice (Fig. 1B).

Before infection, there was no difference in neutrophil concentrations in BAL fluid of protease-deficient and wildtype mice (Fig. 2). The influx of neutrophils into the lungs of protease-deficient and wild-type mice after infection was similar, which confirmed that neutrophil transmigration was unaffected by the absence of serine proteases (Fig. 2).

Lung homogenates and BAL fluid supernatants from mice of each genotype were assayed for inflammatory markers in lungs. The CXC chemokine KC (but not MIP-2) concentration measured in whole lung homogenates was significantly higher in wild-type animals compared with protease-deficient mice (Fig. 3). No difference in TNF- $\alpha$ levels was measured in lungs from protease-deficient and -replete mice (data not shown). Bronchoalveolar lavage levels of all cytokines and chemokines did not differ between protease genotypes (data not shown). MIP-2 and KC tissue concentrations correlated with bacterial burden in the lungs (Fig. 4), suggesting that airway inflammation was only indirectly related to the presence (or absence) of a particular serine protease.

Effect of serine proteases on opsonins in the murine lung. Antibody levels measured in BAL fluid using ELISA and immunoblot analyses were significantly greater in CGdeficient compared with wild-type littermates inoculated with 
A

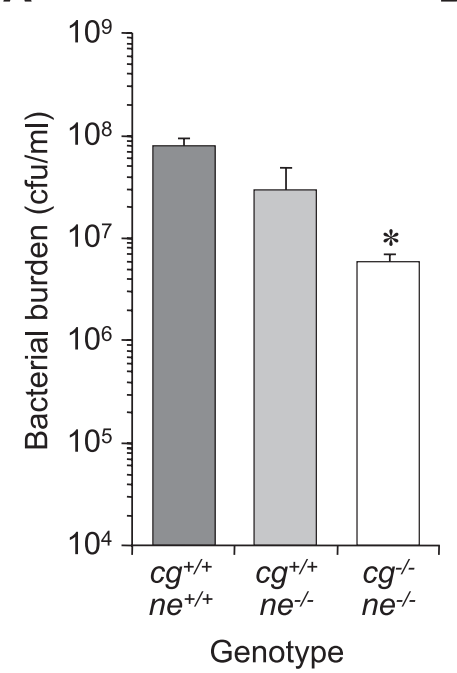

B



Figure 1. (A) Bacterial load in right lung homogenates from $\mathrm{cg}^{+/+} n e^{+/+}$ $(n=16), \mathrm{cg}^{+/+} n e^{-/-}(n=14)$, and $\mathrm{cg}^{-/-} n e^{-/-}(n=16)$ mice $3 \mathrm{~d}$ after intratracheal inoculation with Pseudomonas-laden beads. The mice lacking both serine proteases had significantly lower bacterial burden compared with wild-type controls (Kruskal Wallis test, $p=0.01$ ). (B) Bacterial burden in the

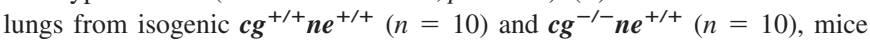
following intratracheal instillation of Pseudomonas. Right lung homogenates were obtained $3 \mathrm{~d}$ after infection. Mice lacking $\mathrm{CG}\left(\mathrm{cg}^{-/-}\right)$had significantly lower bacterial counts than that detected in CG-replete mice $\left(\mathrm{cg}^{+/+}\right)$(Mann Whitney test, $p=0.01$ ).

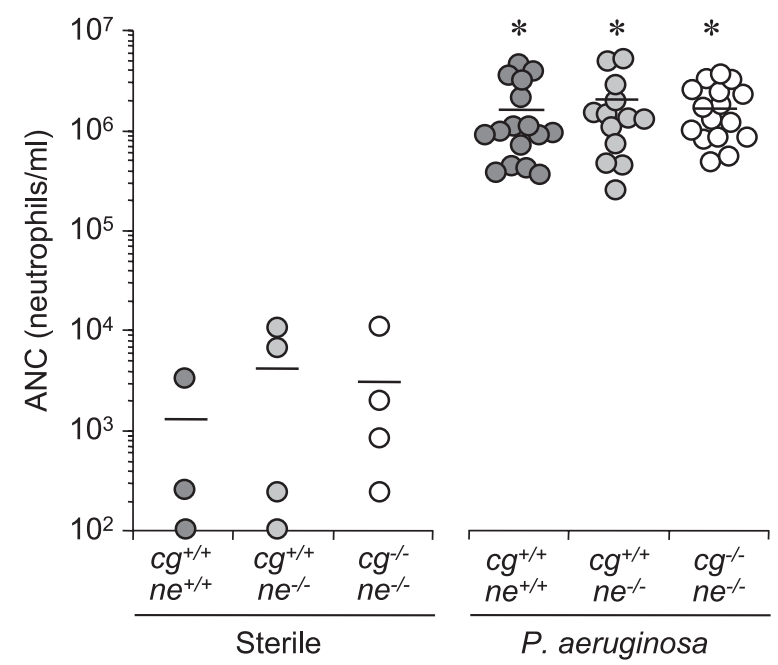

Figure 2. Absolute neutrophil concentrations in the lungs from $\mathrm{cg}^{+/+} n e^{+/+}$, $\mathrm{cg}^{+/+} n e^{-/-}$, and $\mathrm{cg}^{-/-} n e^{-/-}$mice inoculated with sterile or Pseudomonasladen beads. Data represented as means. A marked increase in lavage ANC was found in all mouse genotypes after infection (ANOVA, $p<0.01$ ), but there was no difference in neutrophil influx between mice replete or deficient in serine proteases

Pseudomonas-laden agar beads (Fig. 5 A). A similar relationship was noted between isogenic, CG-deficient and CG-replete mice (Fig. 5 B). Our analyses did not reveal a difference in airway immunoglobulin concentrations between NE-replete and NE-deficient strains. In addition, there was no difference in antibody concentrations in the lungs of uninfected, protease-deficient and -replete mice (data not shown).

Even though maintained in a full-barrier facility, the mice had been previously exposed to $P$. aeruginosa, a ubiquitous,
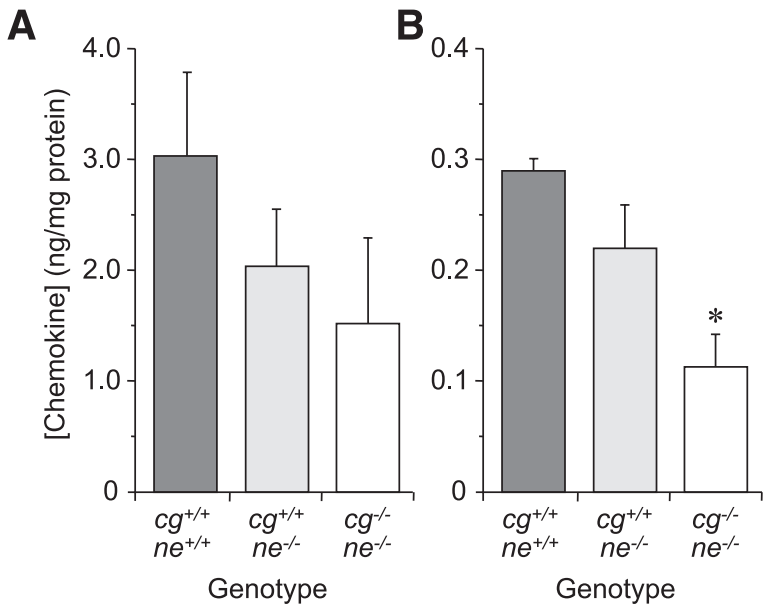

Figure 3. Chemokine (A) MIP-2 and $(B) \mathbf{K C}$ concentrations in lung homogenates from $\mathrm{cg}^{+/+} n e^{+/+}, \mathrm{cg}^{+/+} n e^{-/-}$, and $\mathrm{cg}^{-/-} n e^{-/-}$mice $3 \mathrm{~d}$ after intratracheal instillation of Pseudomonas-laden beads. Data represented as mean \pm SEM. The mice lacking both serine proteases had lower tissue KC concentrations compared with wild-type controls (Kruskal Wallis test, $p=0.03$ ), while differences in MIP2 levels did not achieve statistical significance $(p=0.15)$.
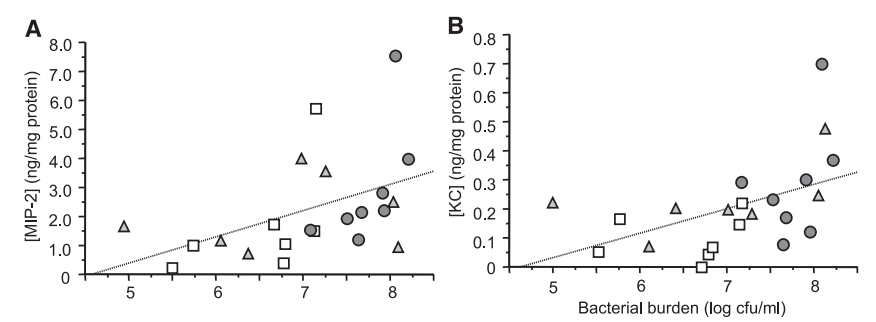

Figure 4. The relationship between bacterial load and CXC chemokine (A) MIP-2 and (B) KC concentrations in lung homogenates from isogenic $\mathrm{cg}^{+/+} n e^{+/+}$(circles), $\mathrm{cg}^{+/+} n e^{-/-}$(triangles) and $\mathrm{cg}^{-/-} n e^{-/-}$(squares) mice $3 \mathrm{~d}$ after Pseudomonas infection. Bacterial burden correlated with MIP-2 concentrations, irrespective of the animals genotype $(r=0.5, p=$ $0.03)$. Similar results were found with $\mathrm{KC}(r=0.5, p=0.01)$.

water-borne organism, in their environment based on the presence of circulating anti- $P$. aeruginosa antibodies (Fig. $6 \mathrm{~A}$ ). Specific, anti-Pseudomonas $\operatorname{IgG}$ and $\operatorname{Ig} \mathrm{A}$ was found in $\mathrm{BAL}$ fluid, especially after infection, which was markedly reduced in wild-type, protease-replete mice (Fig. 6 B).

CG may degrade other opsonins in the lung, resulting in defective bacterial killing and clearance at the airway surface. Collectins, specifically surfactant proteins-A (SP-A) and -D (SP-D), were considered to be potentially susceptible to proteolytic cleavage, resulting in gaps in airway immunity $(25,26)$. SP-A and SP-D levels were measured in lavage fluid from $\mathrm{cg}^{+/+} n e^{+/+}, \mathrm{cg}^{+/+} n e^{-/-}$, and $\mathrm{cg}^{-/-} n e^{-/-}$mice, which did not reveal a difference between protease-replete and protease-deficient animals (Fig. 7).

Bacterial uptake by phagocytes from cathepsin G-deficient mice. We examined the in vivo uptake of GFP-expressing $P$. aeruginosa PAO1 by neutrophils recruited into infected lungs of $c g^{+/+} n e^{+/+}$and $c g^{-/-} n e^{+/+}$mice. Using flow cytometry, pulmonary neutrophils isolated from BAL fluid of CGdeficient mice generally had greater percentage of neutrophils with ingested fluorescent bacteria than CG-replete animals $\left(n=5\right.$ mice per group, $c g^{+/+} n e^{+/+}, 6.7 \pm 1.9 \%$; 


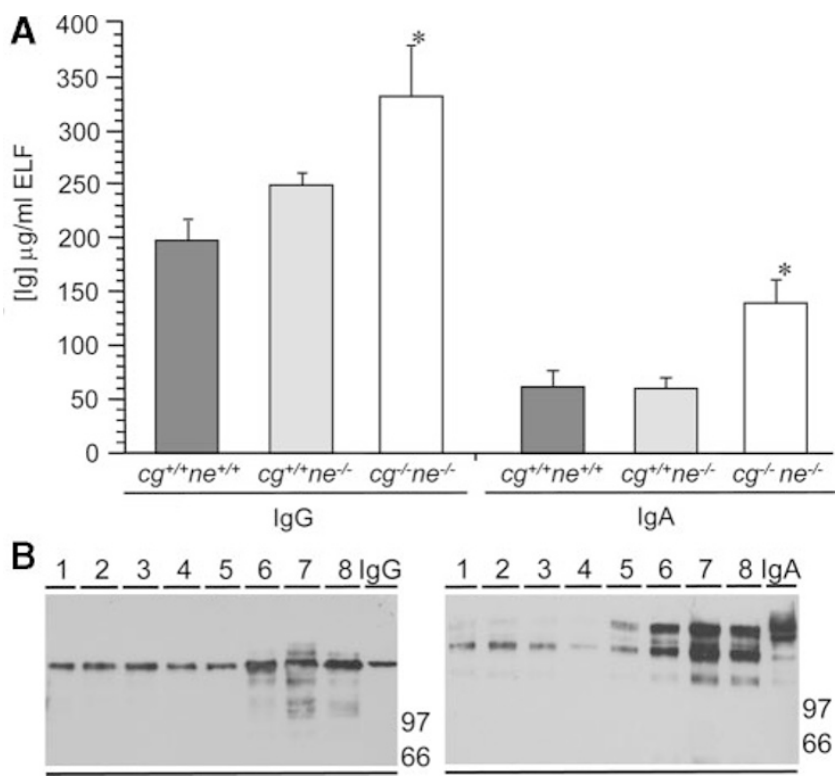

Figure 5. (A) Antibody levels in the lungs of $\mathrm{cg}^{+/+} n e^{+/+}(n=16)$, $c g^{+/+} n e^{-/-}(n=14)$, and $c g^{-/-} n e^{-/-}(n=16)$ mice $3 \mathrm{~d}$ after P. aeruginosa infection. The concentrations of IgG and IgA in respiratory ELF from $c g^{-/} n e^{-/-}$mice were significantly higher compared with $\mathrm{cg}^{+/+} n e^{+/+}$or $c g^{+/+} n e^{-/-}$mice (Kruskal Wallis test, $p=0.05$ and $p<0.001$, respectively). Similar differences between ELF levels in $\mathrm{cg}^{-/-} n e^{-/-}$and $\mathrm{cg}^{+/+} n e^{+/+}$or $\mathrm{cg}^{+/+} n e^{-/-}$were found for IgM concentrations in BAL fluid. (B) Immunoblot analysis of murine antibodies secreted into the lung. Bronchoalveolar lavage fluid from randomly selected $\mathrm{cg}^{+/+} n e^{+/+}$(lanes $\mathbf{1}-\mathbf{4}$ ) and $\mathrm{cg}^{-/-} n e^{+/+}(5-8)$ mice $3 \mathrm{~d}$ after infection. Purified mouse antibodies were used as positive controls (IgG and IgA). Molecular weight standards (kDa) are shown.
A

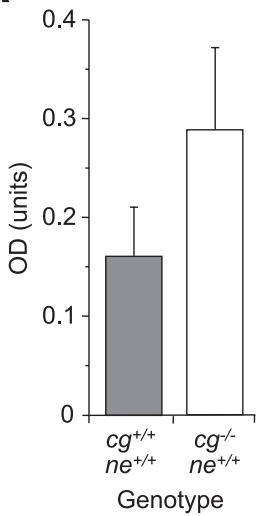

B

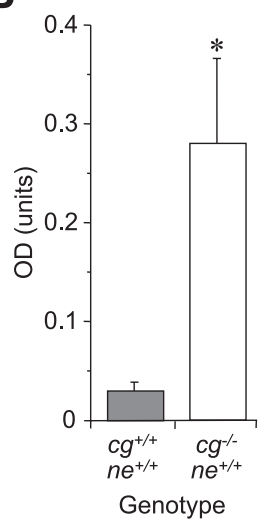

A



B

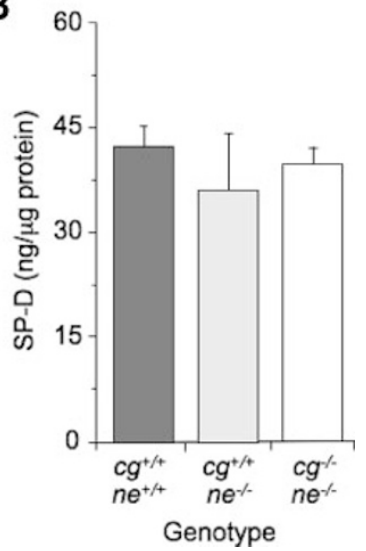

Figure 7. Collectin SP-A $(A)$ and SP-D $(B)$ levels measured in BAL fluid from protease-deficient and wild-type mice after $P$. aeruginosa infection. Three days after intratracheal instillation of Pseudomonas-laden beads, $\mathrm{cg}^{+/+}$ $n e^{+/+}(n=16), \mathrm{cg}^{+/+} n e^{-/-}(n=14)$, and $\mathrm{cg}^{-/-} n e^{-/-}(n=16)$ mice underwent lavage. Similar SP-A and SP-D concentrations were measured in BAL fluid, regardless of the mouse genotype.

\section{DISCUSSION}

Neutrophil elastase has been shown to contribute to pathogenesis of suppurative airway diseases by interfering with bacterial clearance and inciting greater inflammation. However, we found that CG independently hindered the host's ability to clear $P$. aeruginosa from the airway in a mouse model, perhaps related to protease-created defects in extracellular bacterial killing at the epithelial surface. Also, our results indicate that serine proteasemediated effects on airway inflammation are primarily a response to increased $P$. aeruginosa burden in the lungs, and not due to direct interaction between specific proteases and epithelial cells. Finally, there were no differences in neutrophil concentrations within BAL fluid collected from wild-type and protease-deficient mice before and after $P$. aeruginosa infection, showing that the absence of CG or NE did not affect neutrophil migration into the airway.

Given the substantial overlap in substrates and neutralizing antiproteases, it has been difficult to separate the effect of a single protease in vivo. We had the opportunity to reexamine previous observations using animal models completely devoid of individual proteases, in that these animals were genetically altered to be totally deficient of NE, CG, or both. Despite the absence of NE or CG, these animals were phenotypically identical to wild-type mice until challenged with bacteria. Previous studies using these mice have shown that serine proteases $(2,19)$ are important for Gram-negative bacterial killing, but pulmonary infection was not specifically assessed in these models. Given the confinement of $P$. aeruginosa to lungs, earlier studies did not effectively model infection typical of CF.

The Pseudomonas endobronchitis model described in this report allowed us to control the host's genetic background as well as the genotype and virulence factors expressed by infecting organisms, factors difficult to manipulate or evaluate in humans. This approach provides another advantage for these experiments since the agarose beads physically impede the mucociliary escalator. The lung had to rely on alternative mechanisms to clear bacteria from the lungs, including innate and adaptive immunity 
of the airways. Nevertheless, it is unclear whether the difference in bacterial load of CG-deficient mice is related to better $P$. aeruginosa killing or inhibition of bacterial growth, which will be examined in future studies.

Although the protease-deficient mice are housed under pathogen-free conditions, these animals had clearly been exposed to $P$. aeruginosa, a common environmental bacterium. While mice lacking CG had consistently lower bacterial loads, indicating more efficient bacterial clearance or killing, and higher concentrations of specific antibodies in the ELF, it is unclear whether antibody-mediated defenses are important to control $P$. aeruginosa infection. Many anti-Pseudomonas antibodies collected from infected CF patients are nonopsonic (28).

The phagocytic system affords protection against bacterial invasion, yet it also contributes to epithelial cell injury and damage. The extracellular release of catalytically active enzymes can have deleterious effects on the respiratory epithelium, and the protease burden in the bronchiectatic airway overwhelms the existing antiprotease defense. Proteases at the epithelial surface can inhibit or destroy components needed for airway defenses (29), resulting in defective bacterial killing and clearance. Indeed, though relatively resistant to destruction by serine protease, $\beta$-defensin can be inactivated by cysteine proteases (30). The antimicrobial enzyme, lactoferrin, is cleaved by cysteine proteases in CF sputa, resulting in a loss of antimicrobial activity against $P$. aeruginosa (31).

Two recent reports described reduced SP-A and SP-D levels in CF BAL fluid $(25,26)$. Collectins are susceptible to proteolysis by $\mathrm{NE}$ and $\mathrm{CG}$, leading investigators to postulate that unopposed neutrophil-derived serine proteases digest SP-A and create a breach in CF airway defenses. However, we did not find any differences in SP-A and SP-D concentrations in BAL fluid collected from protease-deficient and replete mice after infection with bacteria. The discrepancy of our findings with those described in patients was surprising, and are likely related to differences in the chronicity of Pseudomonas infection and intensity of the inflammatory response in the CF lung compared with that seen in the murine agar bead model.

Neutrophil elastase has been shown to stimulate epithelial inflammation, inducing the CXC-chemokine, IL-8, through a $\mathrm{NF}-\kappa \mathrm{B}$-dependent pathway $(4,5)$, and we expected to find less inflammation in the lungs of protease-deficient mice following infection. Conversely, neutrophil-derived serine proteases cleave $P$. aeruginosa flagellin, a potent inflammatory stimulus (32), and degradation of this virulence factor blunted expression of host defense genes in airway cell lines (20). In this model, the proteases only indirectly affected inflammatory response of the lungs following $P$. aeruginosa infection. Our results showed that serine protease-mediated effects on airway inflammation in the Pseudomonas-agar bead model was a response to increased bacterial burden in the lungs and not due to direct interaction between specific proteases and epithelial cells. Because the bacteria are encased in agar beads, it is possible that for some $P$. aeruginosa, their microenvironment was altered (i.e. hypoxia) such that flagellin was not expressed (33).

In conclusion, although $\mathrm{NE}$ has a principal role in the pathogenesis of suppurative airway diseases, such as CF, we found that $\mathrm{CG}$ also contributes to the infectious complications. We have shown that neutral serine proteases have differential effects in the infected lung. Specifically, CG hindered clearance of $P$. aeruginosa from the murine lung, which we suspect are related to $g a p(s)$ in airway defenses created by high concentrations of unopposed protease. The resultant increase in bacterial load then stimulated a greater inflammatory response from the epithelium. We also expect that such mouse models will permit identification of candidate proteins central to bacterial clearance in the airway and could potentially provide new therapeutic targets.

Acknowledgments. The authors wish to thank Jeff Whitsett and William Hull (Cincinnati Children's Hospital Medical Center, Cincinnati, $\mathrm{OH}$ ) for their assistance in measuring surfactant protein levels in lavage fluid, and Steven Shapiro (Harvard University, Boston, MA) for providing the mouse models. We are also grateful to Sharon Favors and Mary Baumann for their expert technical support. The GFPexpressing $P$. aeruginosa $\mathrm{PAO} 1$ strain was a gift from Pradeep Singh, M.D. (University of Iowa).

\section{REFERENCES}

1. Konstan MW, Hilliard KA, Norvell TM, Berger M 1994 Bronchoalveolar lavage findings in cystic fibrosis patients with stable, clinically mild lung disease suggest ongoing infection and inflammation. Am J Respir Crit Care Med 150:448-454

2. Belaaouaj A, McCarthy R, Baumann M, Gao Z, Ley TJ, Abraham SN, Shapiro SD 1998 Mice lacking neutrophil elastase reveal impaired host defense against gramnegative bacterial sepsis. Nat Med 4:615-618

3. Odeberg H, Olsson I 1976 Mechanisms for the microbicidal activity of cationic proteins of human granulocytes. Infect Immun 14:1269-1275

4. Nakamura H, Yoshimura K, McElvaney NG, Crystal RG 1992 Neutrophil elastase in respiratory epithelial lining fluid of individuals with cystic fibrosis induces interleukin-8 gene expression in a human bronchial epithelial cell line. J Clin Invest 89:1478-1484

5. Walsh DE, Greene CM, Carroll TP, Taggart CC, Gallagher PM, O'Neill SJ, McElvaney NG 2001 Interleukin-8 up-regulation by neutrophil elastase is mediated by MyD88/IRAK/TRAF-6 in human bronchial epithelium. J Biol Chem 276:35494-35499

6. Fick RB, Naegel GP, Squier SU, Wood RE, Gee JB, Reynolds HY 1984 Proteins of the cystic fibrosis respiratory tract. Fragmented immunoglobulin $\mathrm{G}$ opsonic antibody causing defective opsonophagocytosis. J Clin Invest 74:236-248

7. Tosi MF, Zakem H, Berger M 1990 Neutrophil elastase cleaves C3bi on opsonized Pseudomonas as well as CR1 on neutrophils to create a functionally important opsonin receptor mismatch. J Clin Invest 86:300-308

8. Hunter MG, Druhan LJ, Massullo PR, Avalos BR 2003 Proteolytic cleavage of granulocyte colony-stimulating factor and its receptor by neutrophil elastase induces growth inhibition and decreased cell surface expression of the granulocyte colonystimulating factor receptor. Am J Hematol 74:149-155

9. Porteu F, Brockhaus M, Wallach D, Engelmann H, Nathan C 1991 Human neutrophil elastase releases a ligand-binding fragment from the 75-kDa tumor necrosis factor (TNF) receptor. Comparison with the proteolytic activity responsible for shedding of TNF receptors from stimulated neutrophils. J Biol Chem 266: 18846-18853

10. Travis J 1988 Structure, function, and control of neutrophil proteinases. Am J Med $84: 37-42$

11. Schuster A, Fahy JV, Ueki I, Nadel JA 1995 Cystic fibrosis sputum induces a secretory response from airway gland serous cells that can be prevented by neutrophil protease inhibitors. Eur Respir J 8:10-14

12. Reilly CF, Travis J 1980 The degradation of human lung elastin by neutrophil proteinases. Biochim Biophys Acta 621:147-157

13. Tralau T, Meyer-Hoffert U, Schroder JM, Wiedow O 2004 Human leukocyte elastase and cathepsin $\mathrm{G}$ are specific inhibitors of C5a-dependent neutrophil enzyme release and chemotaxis. Exp Dermatol 13:316-325

14. Bank U, Ansorge S 2001 More than destructive: neutrophil-derived serine proteases in cytokine bioactivity control. J Leukoc Biol 69:197-206

15. Lomas DA, Stone SR, Llewellyn-Jones C, Keogan MT, Wang ZM, Rubin H, Carrell RW, Stockley RA 1995 The control of neutrophil chemotaxis by inhibitors of cathepsin G and chymotrypsin. J Biol Chem 270:23437-23443

16. Shafer WM, Shepherd ME, Boltin B, Wells L, Pohl J 1993 Synthetic peptides of human lysosomal cathepsin $\mathrm{G}$ with potent antipseudomonal activity. Infect Immun 61:1900-1908

17. Reeves EP, Lu H, Jacobs HL, Messina CG, Bolsover S, Gabella G, Potma EO, Warley A, Roes J, Segal AW 2002 Killing activity of neutrophils is mediated through activation of proteases by $\mathrm{K}^{+}$influx. Nature 416:291-297 
18. Cantin AM, Woods DE 1999 Aerosolized prolastin suppresses bacterial proliferation in a model of chronic Pseudomonas aeruginosa lung infection. Am J Respir Crit Care Med 160:1130-1135

19. MacIvor DM, Shapiro SD, Pham CT, Belaaouaj A, Abraham SN, Ley TJ 1999 Normal neutrophil function in cathepsin-G-deficient mice. Blood 94:4282-4293

20. Lopez-Boado YS, Espinola M, Bahr S, Belaaouaj A 2004 Neutrophil serine proteinases cleave bacterial flagellin, abrogating its host response-inducing activity. J Immunol 172:509-515

21. van Heeckeren AM, Tscheikuna J, Walenga RW, Konstan MW, Davis PB, Erokwu B, Haxhiu MA, Ferkol TW 2000 Effect of Pseudomonas infection on weight loss, lung mechanics, and cytokines in mice. Am J Respir Crit Care Med 161:271-279

22. Rennard SI, Basset G, Lecossier D, O’Donnell KM, Pinkston P, Martin PG, Crystal RG 1986 Estimation of volume of epithelial lining fluid recovered by lavage using urea as marker of dilution. J Appl Physiol 60:532-538

23. Ferkol T, Mularo F, Hilliard J, Lodish L, Perales JC, Ziady AG, Konstan MW 1998 Transfer of the gene encoding human alpha ${ }_{1}$-antitrypsin into pulmonary alveolar macrophages via the mannose receptor. Am J Respir Cell Mol Biol 18:591-601

24. LeVine AM, Bruno MD, Huelsman KM, Ross GF, Whitsett JA, Korfhagen TR 1997 Surfactant protein A-deficient mice are susceptible to group B streptococcal infection. J Immunol 158:4336-4340

25. Noah TL, Murphy PC, Alink JJ, Leigh MW, Hull WM, Stahlman MT, Whitsett JA 2003 Bronchoalveolar lavage fluid surfactant protein-A and surfactant protein-D are inversely related to inflammation in early cystic fibrosis. Am J Respir Crit Care Med 168:685-691

26. Rubio F, Cooley J, Accurso FJ, Remold-O'Donnell E 2004 Linkage of neutrophil serine proteases and decreased surfactant protein-A (SP-A) levels in inflammatory lung disease. Thorax 59:318-323
27. Berger M, Norvell TM, Tosi MF, Emancipator SN, Konstan MW, Schreiber JR 1994 Tissue-specific Fc gamma and complement receptor expression by alveolar macrophages determines relative importance of $\mathrm{IgG}$ and complement in promoting phagocytosis of Pseudomonas aeruginosa. Pediatr Res 35:68-77

28. Eichler I, Joris L, Hsu YP, Van Wye J, Bram R, Moss R 1989 Nonopsonic antibodies in cystic fibrosis. Pseudomonas aeruginosa lipopolysaccharide-specific immunoglobulin $\mathrm{G}$ antibodies from infected patient sera inhibit neutrophil oxidative responses. J Clin Invest 84:1794-1804

29. Taggart CC, Greene CM, Carroll TP, O’Neill SJ, McElvaney NG 2005 Elastolytic proteases: inflammation resolution and dysregulation in chronic infective lung disease. Am J Respir Crit Care Med 171:1070-1076

30. Taggart CC, Greene CM, Smith SG, Levine RL, McCray PB, O'Neill S, McElvaney NG 2003 Inactivation of human beta-defensins 2 and 3 by elastolytic cathepsins. J Immunol 171:931-937

31. Rogan MP, Taggart CC, Greene CM, Murphy PG, O’Neill SJ, McElvaney NG 2004 Loss of microbicidal activity and increased formation of biofilm due to decreased lactoferrin activity in patients with cystic fibrosis. J Infect Dis 190:1245-1253

32. Hybiske K, Ichikawa JK, Huang V, Lory SJ, Machen TE 2004 Cystic fibrosis airway epithelial cell polarity and bacterial flagellin determine host response to Pseudomonas aeruginosa. Cell Microbiol 6:49-63

33. Bragonzi A, Worlitzsch D, Pier GB, Timpert P, Ulrich M, Hentzer M, Andersen JB, Givskov M, Conese M, Doring G 2005 Nonmucoid Pseudomonas aeruginosa expresses alginate in the lungs of patients with cystic fibrosis and in a mouse model J Infect Dis 192:410-419 